\title{
The Comparison of the Balanus improvises (Crustacea: Cirripeia) Growth, Population Dynamics and Larval Recruitment in the Southern Coasts of the Caspian Sea
}

\author{
Mohammad Zeinalipour \\ Department of Basic Sciences, Khajeh Nasir Pardis, Farhangian University, Kerman 7616613785, Iran
}

\begin{abstract}
Population dynamics of the Balanus improvises (Crustacean: Cirripedia) was studied in three stations Amirabad, Khazarabad in the eastern part and Noor in the central part of the Southern Coasts of the Caspian Sea. Sampling procedure was carried out monthly from July 2007 to July 2008. In this study longitudinal diameter aperture (orifice or opercula diameter) of 4118 individuals as well as dry weight and ash free dry weight of 141 barnacles were measured. Barnacle population density decreased in all three stations during autumn and winter. Barnacle density in Khazarabad were significantly higher than the other two stations $(P>0 / 05)$. In this study, for dry weight and ash free dry weight maximum 247 and $122 \mathrm{mg}$ and minimum 0/5 and 0/25 mg were obtained respectively. Emergence of a young cohort in March 2008, indicates the reproduction season and larval recruitment at this time. Also the frequency of the larval recruitment from April 2004 until mid-summer had increased. Opercula diameter of B. improvisus correlated with dry weight $\left(R^{2}=0 / 87, n=115\right)$ and ash free dry weight $\left(R^{2}=0 / 77, n=115\right)$. In addition, two equations for correlation of opercula diameter with dry weight $\left(\mathrm{W}=0 / 49 \mathrm{~L}^{2 / 6}, \mathrm{Re}=14\right)$ and ash free dry weight $\left(\mathrm{W}=0 / 16 \mathrm{~L}^{2 / 81}, \mathrm{Re}=18 / 8\right)$ for this species were calculated.
\end{abstract}

Key words: Balanus improvises, larval recruitment, population dynamic, opercula diameter.

\section{Introduction}

Large temporal and spatial variation exhibit in population dynamics and density for benthic animals such as bivalves and barnacles. So a principal aim of ecological studies is to understand factors influencing local patterns on the distribution and abundance of benthic populations [1-6]. Acorn barnacles are an important part of intertidal communities' world- wide that are often used as representative organisms to study processes at coastal and intertidal ecology. As barnacles have a bi-partic lifecycle (sessile adults and planktonic larvae), the population dynamics, distribution, abundance and persistence of barnacle zone have controlled by recruitment of larvae from the plankton and subsequent on-shore mortality events which are often density dependant and sensitive to climatic and hydrographic changes [7, 8]. Studding

Corresponding author: Mohammad Zeinalipour, Ph.D., professor, research fields: marine invertebrate biology and ecology. E-mail: mazeinalipor@yahoo.com. the population dynamics of barnacles and their subsequent spatial variation is essential to further understand the structure and dynamics of intertidal communities [6]. Balanus improvises are with a wide spread species in many regions of the temperate subtropical zones of the world oceans from the Atlantics coasts of America to Europe and then to the west of Africa, the Mediterranean and Red sea, Australia, Japan, Hawaii and the pacific coast of the north and south America [9, 10]. In the Soviet Union, the species inhabits the Baltic, Black and Caspian seas and the Sea of Azov [10]. B. improvisus was introduced with the opening of the Volga-Don Canal in 1954 and established populations in the Caspian Sea from the Black Sea in 1955 [9, 10]. The transfer of ballast water between international ports is suggested as a potential vector of these invasions. Subsequently B. improvisus dispersed quickly and nowadays they can be found throughout the Caspian Sea, except for areas with cold and freshwater 
conditions. Two species of barnacle namely $B$. improvisus and B. eburneus are presented in the Caspian Sea [9]. But only B. improvisus has been found in the south Caspian Sea [10]. B. improvisus have pelagic larvae and benthic species in adults [1, 11]. In this paper some aspect of the population dynamics of established alien species Balanus improvisus is described in the southern coast of the Caspian Sea.

\section{Materials and Methods}

A one year, monthly investigation of Balanus improvisus population structure was conducted from July 2007 to July 2008 in Amirabad port (36 51'40" N, $53^{\circ} 22^{\prime 29 " ~ E), ~ K h a z a r a b a d ~ E s t u a r y ~(36 ~} 48^{\prime} 53^{\prime \prime} \mathrm{N}$, $53^{\circ} 6^{\prime} 43^{\prime \prime}$ E) in eastern part and Noor coasts $\left(36^{\circ} 35^{\prime} 7^{\prime \prime}\right.$ $\mathrm{N}, 52^{\circ} 2^{\prime 28} " \mathrm{E}$ ) in the central part at the southern shores of the Caspian Sea (Fig. 1). In three sites artificial reefs support the population of $B$. improvises. All sites have gently sloping rock platforms which supported populations of $B$. improvisus. The other invertebrates, on all shores were Mytilaster lineatus (Bivalve), Rhithropanopeus harrisii, Gammarus sp. \& Palemon sp. (Crustacean) and Nereis sp. (Polychaete). The samples were collected by a quadrate (sampling area $0.45 \mathrm{~cm}^{2}, 3$ samples per each station, in any month, total 9 samples) from rocks that placed for breakwater. Samples were sieved through a $0.25 \mathrm{~mm}$ net and then deep frozen at $-20{ }^{\circ} \mathrm{C}$. Regarding to plenty of Barnacle in the specimens (170 in average), one of the specimens was measured for orifice or opercula diameter $(0.01 \mathrm{~mm}$ precision) by vernier calipers $( \pm 0.1 \mathrm{~mm})$ [11-13]. Barnacles of the three specimens were counted and their average was taken as station frequency. Dry weight was obtained $( \pm 0.001$ g) after drying the specimens at $60{ }^{\circ} \mathrm{C}$ for $48 \mathrm{~h}$ also ash weight were obtained $( \pm 0.001 \mathrm{~g})$ after the specimens were burned in an electrical furnace for 1 hours in 600 ${ }^{\circ} \mathrm{C}$. Dry weight was subtracted from ash weight to obtain weight of organic material. During sampling, inshore water temperatures (mercury thermometer, $\pm 0.1^{\circ} \mathrm{C}$ ) and salinity (At ago refractometer, $\pm 1 \%$ ) were measured monthly. In this study longitudinal diameter aperture (orifice or opercula diameter) of 4,118 individuals as well as dry weight and ash free dry weight of 141 barnacles were measured. To obtain length opercula diameter relations to dry weight and ash free dry weight, regression analysis and exponential equation $\mathrm{W}=\mathrm{q} \cdot \mathrm{L}^{\mathrm{b}}$ was used, which $\mathrm{W}$ is dry or organic material weight, $\mathrm{q}$ is a constant, $\mathrm{b}$ is power, and $L$ is diameter aperture $[7,14]$. Duncanne test was used to compare length average difference of cohorts $(P<0.05)$, and Chi Square test in 95\% level was used to compare length frequencies of stations. The number of cohorts, mean size of each cohort, and number of individuals in each cohort for all locations were

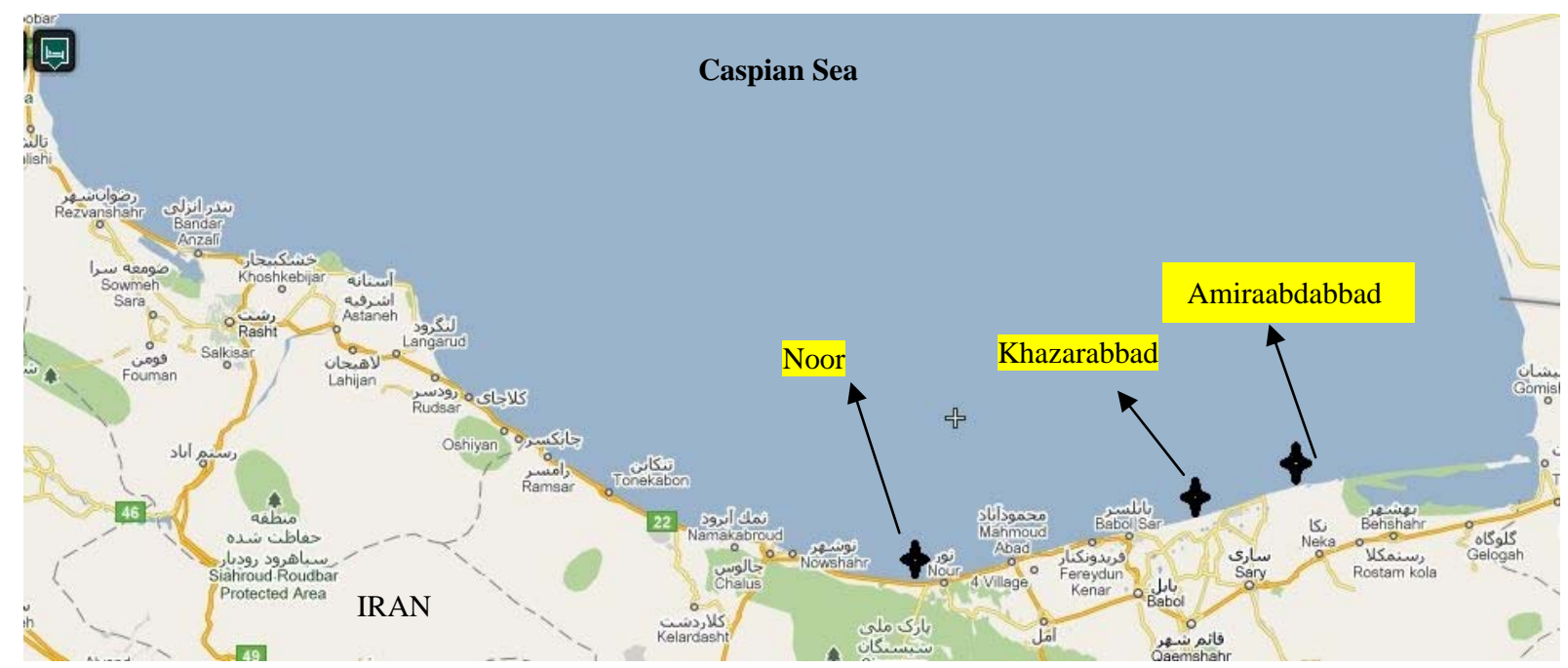

Fig. 1 Sampling station in the southern shores of Caspian Sea. 

and Larval Recruitment in the Southern Coasts of the Caspian Sea

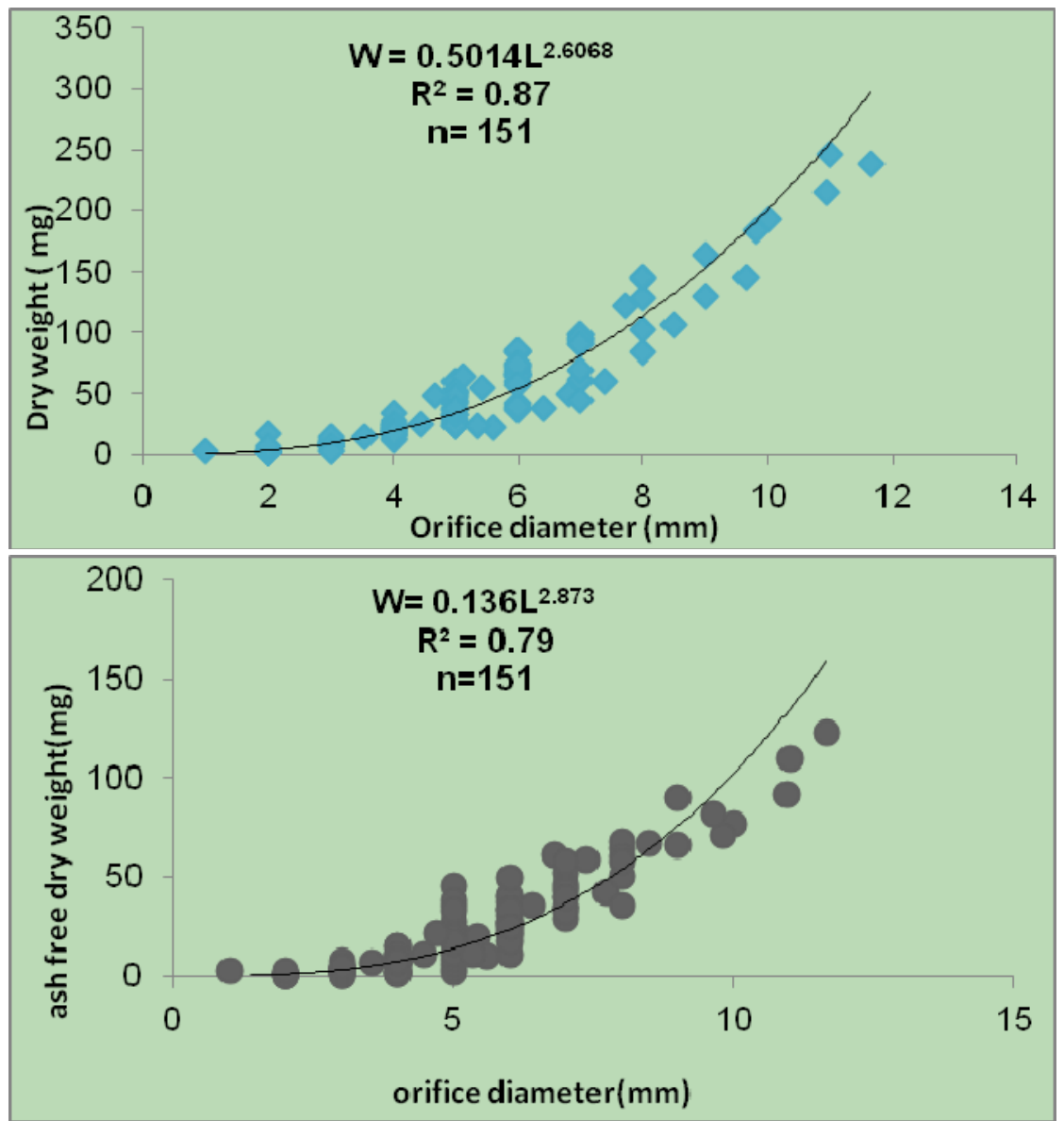

Fig. 2 Relationship between orifice diameter (mm) with Dry weight (up) and ash free dry weight (down).

estimated using electronic length frequency analysis (ELEFAN). ELEFAN separates cohorts by generating a regression model from the population data using Bhattacharya's method [4-6].

\section{Result and Discussion}

\subsection{Population Dynamics}

The monthly changes in population structure is shown by the histograms (Fig. 3). In July 2007, the B.improvisus population at Amirabbad consisted of two cohorts, the cohort A (mean Orificial Diameter: $5.82 \mathrm{~mm}$ ) and cohort B (mean OD: $1.93 \mathrm{~mm}$ ). Cohorts $A \& B$ were combined in August with name $A+B$. The cohort $A+B$ remained stable and identifiable to February 2008. An intense settlement was, however, observed in April 2008 which resulted in a new cohort joining the population with name cohort $\mathrm{D}(2.75 \mathrm{~mm})$. This cohort was remained in June 2008. Small cohorts such as cohort $\mathrm{C}(0.75 \mathrm{~mm})$ and $\mathrm{E}(1.4 \mathrm{~mm})$ also identifiable in November and July 2008. But this cohorts small in density and disappeared during the same month. In July 2007, B.improvisus population at Khazarabbad consisted of two cohorts; A (5.21 mm) and B (3.22 mm). The cohort B was remained stable and identifiable in all investigation period. But cohort A disappeared in September 2007. An intense settlement was, however, observed in April 2008 which resulted in a new cohort joining to population with name cohort C (2.5 mm). This cohort was remained to final investigation period. In July 2007, the B.improvisus population at Noor consisted of two cohorts, the cohort A (mean O-D $7.6 \mathrm{~mm}$ ) and cohort B (mean O-D $3.64 \mathrm{~mm}$. These cohorts were combined in august in $\mathrm{A}+\mathrm{B}$ cohort. The cohort $\mathrm{A}+\mathrm{B}$ remained stable and identifiable to May 2008. An intense settlement was, however, observed in February 2008 
The Comparison of the Balanus improvises (Crustacea: Cirripeia) Growth, Population Dynamics and Larval Recruitment in the Southern Coasts of the Caspian Sea
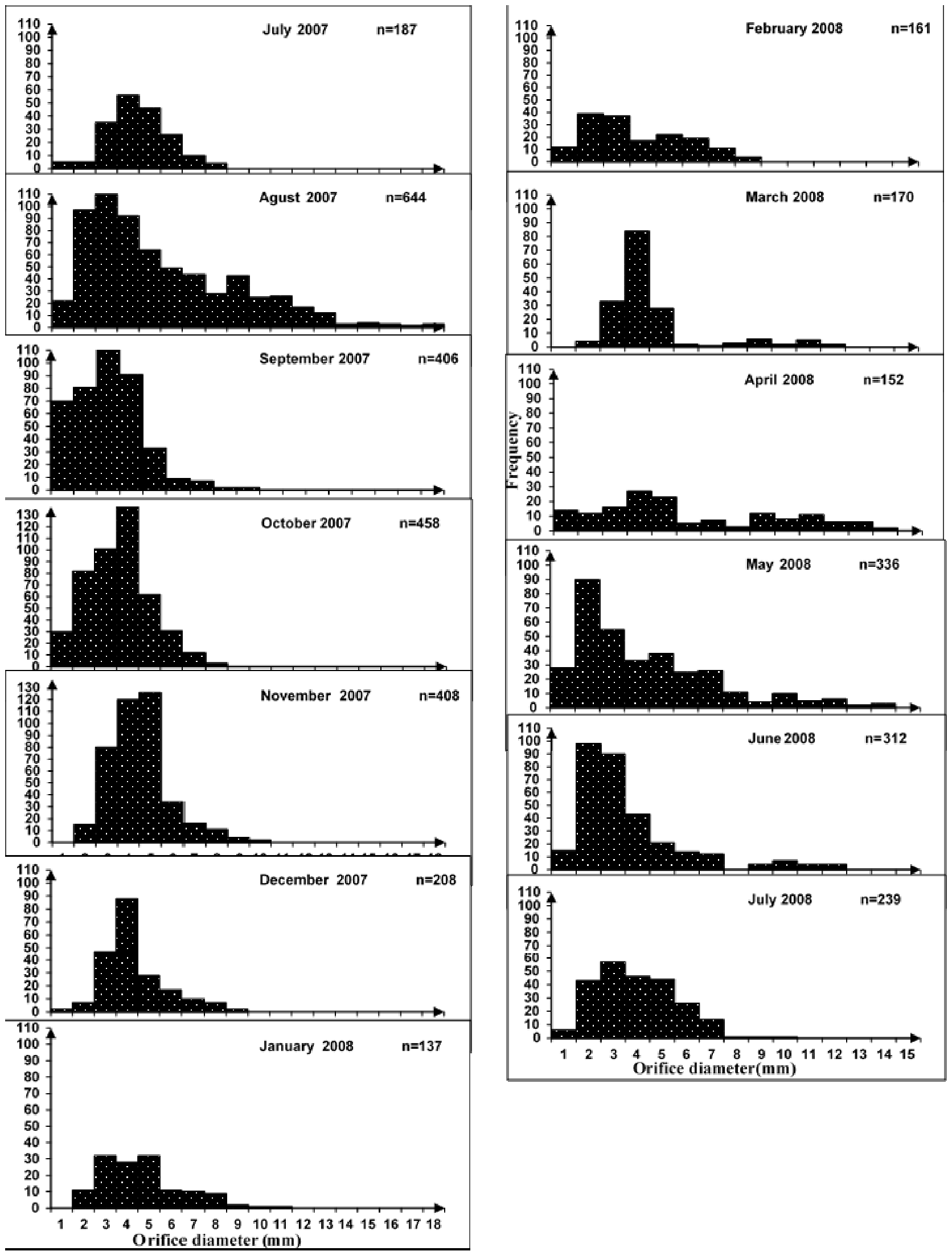

Fig. 3 Monthly SL frequency distribution of B. improvisus collected during July 2007 to July 2008 in the study area. 
which resulted in a new cohort joining the population (the cohort C). This cohort was remained to final investigation period.

\subsection{Relationship between Orifice Diameter and Weight}

Correlations of Orifice diameter with dry weight, and also with Ash free dry weight in Balanus improvises were analyzed in this study by data of all stations (Fig. 2). $\mathrm{R}^{2}$ values in all cases show exact correlation between Orifice diameter and dry weight, also ash free dry weight. In all three stations, equation $\mathrm{W}=0.5014 \mathrm{~L}^{2.6068}$ for correlation of Orifice diameter and Dry weight $\left(\mathrm{R}^{2}=0.87, \mathrm{n}=151\right)$, and equation $\mathrm{W}=0.136 \mathrm{~L}^{2.873}$ for correlation of Orifice diameter and Ash free dry weight $\left(\mathrm{R}^{2}=0.79, \mathrm{n}=151\right)$ were obtained.

\subsection{Water temperature and salinity variation}

In 2007, inshore water temperatures at Amirabbad $25{ }^{\circ} \mathrm{C}$ in June 2007 to $28.6{ }^{\circ} \mathrm{C}$ in September, then dropped gradually to $10^{\circ} \mathrm{C}$ in March, and increase to final investigation period. In Khazarabbd inshore water temperature was changed from $19.5{ }^{\circ} \mathrm{C}$ in start study to maximum 28.5 in September and gradually decreased to $7.5{ }^{\circ} \mathrm{C}$ in March. Then temperature in Khazarabbad was increased to 24.5 in August. Also inshore water temperature in Noor station show similar pattern to other station. In 2007, salinity at Noor and Amirabbad was quite stable at 12.5 ppt. In Khazarabbad station salinity was stable from June to December 2007 with 12.5 ppt, but decreasing to 3 ppt in April 2008. Salinity was reached to 12 ppt in Khazarabbad from April to June 2008.

Aquatic invertebrates show a lot of changes in their growth rate annually. Growth of these animals is a sign of their population and environmental conditions. In fact, growth is a kind of physiologic response to environmental conditions. Various environmental factors affected on growth rate of barnacle. In Balanus, growth rate changes regarding to age, size, population density, and environmental conditions, including food availability, environment temperature and salinity. Food is one of the important factors that affects on growth of animals, since it is a support for their needed energy. Population density is another important factor on growth of these animals. By increasing of population density, intergroup competition for food increases and so growth rate decreases $[2,4,7,15]$. Settlement intensity and post-recruitment mortality of barnacle varied between sites, possibly due to spatial variation in salinity, physical transport of larvae and abundance of food in the water column also different in pollution rate. The population dynamics of $B$. improvisus in southern shore of Caspian Sea exhibit spatial and temporal variation. The population structure and geographic distribution is strongly affected by annual recruitment and larval supply, which can be further influenced by anthropogenic induced climatic changes. In Amirabbad harbor due to the greater impact of human pollution and Macrophytic algae growth obvious irregularities to be seen in some times during the study period. Growth of macrophyt algae can be seen in some months [5]. This algae were covered all levels of artificial reef. Other studies have pointed of the impact of climate change and human pollution on barnacle populations [7]. Barnacle growth in this study diminishes during winter and increases from late winter and during spring. Temperature decrement and then decrease in food, is a factor that adjusted this growth decrement. This study showed that there is approximately exact correlation between orifice diameter and dry weight in B. improvisus $\left(\mathrm{R}^{2}=0.87\right)$. This correlation was also seen for Orifice diameter and ash free dry weight $\left(\mathrm{R}^{2}=0.79\right)$. Therefore, orifice diameter is a suitable tool for estimating dry weight, ash free dry weight, and Biomass in Balanus improvises. In some other invertebrates, including Bivalves, shell length and shell height were used as a tool for estimating the weight $[5,6]$. Most intertidal invertebrates depend on the successful settlement of dispersing larvae to maintain populations. Successful recruitment 
The Comparison of the Balanus improvises (Crustacea: Cirripeia) Growth, Population Dynamics and Larval Recruitment in the Southern Coasts of the Caspian Sea

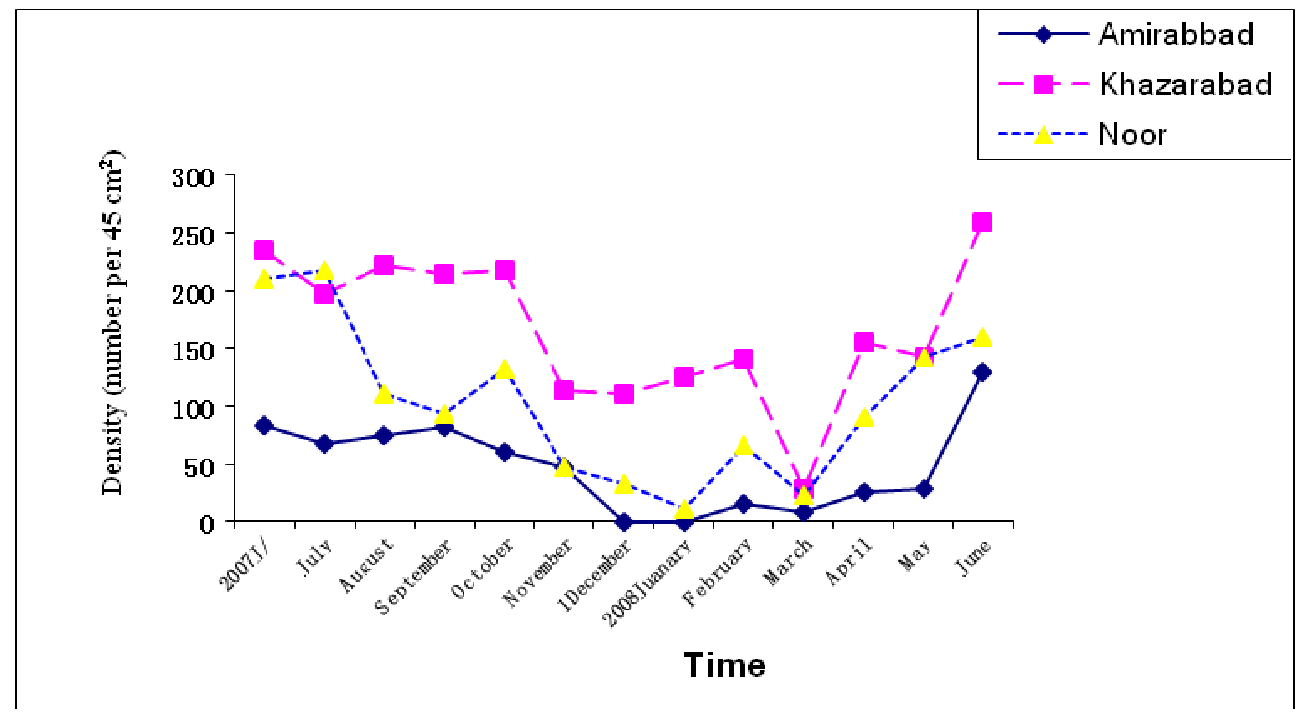

Fig. 4 Comparison of barnacle density in three stations.

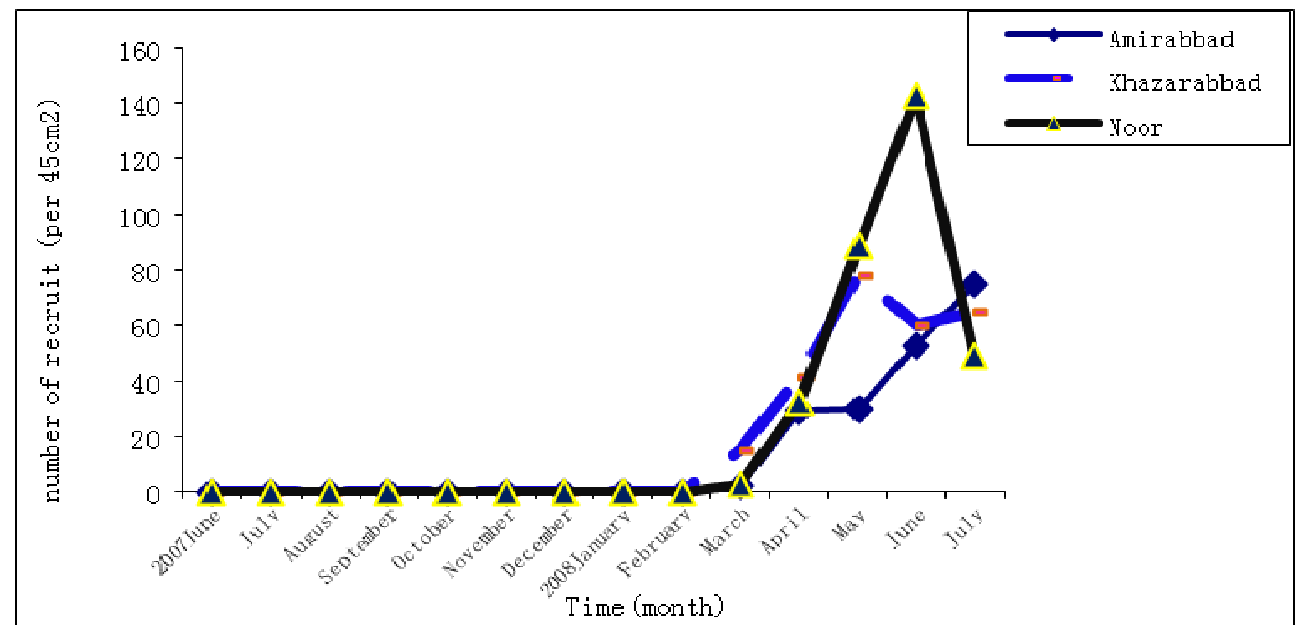

Fig. 5 Comparison of B.improvisus recruited larvae changes in three stations.

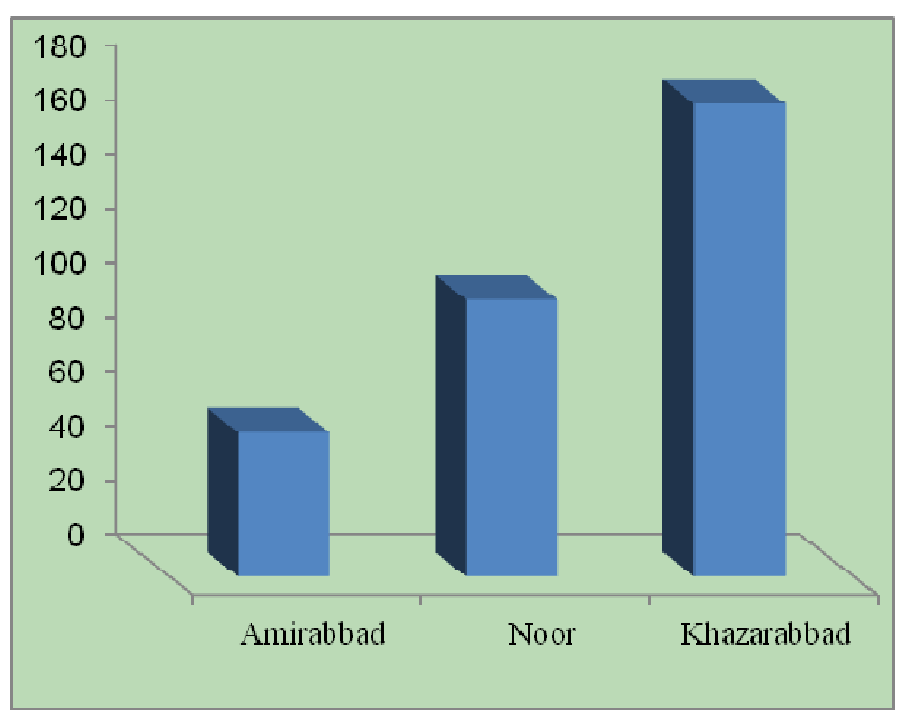

Fig. 6 Comparison of barnacle number in three stations (mean in $45 \mathrm{~cm}^{2}$ ). 
to the adult population may be highly variable in space and time, reflecting the demographic diversity of a population [4, 7]. Recruitment links between planktonic larves and benthic adult components of life cycles, acting as filter between life history stages. Consequently, variation in recruitment may influence the population dynamics of a species and ultimately, community structure also recruitment includes both the larval settlement process and the early survival of settlers. Differences in larval recruitment between stations (Fig. 6) probably could be related to pollution, food availability and space competitive of the barnacle larvae and larvae of Mytilaster lineatus (Bivalvia: mytilidae). The khazarabbad estuary population had significantly higher densities of B. improvisus than the Amirabbad and Noor population over the entire period of sampling (Fig. 6). There was a trend of decreasing density with time at three stations. A notable increase in density occurred in March 2008 (Fig. 5) as a result of recruitment of Juveniles into the population. Comparison of the population density during the study period shows a gradual decrement at all stations in autumn and winter (Fig. 4), probably caused by thermal stress. Increase in Population density in the spring and summer is due to the addition of the juveniles to earlier population.

\section{References}

[1] Caffey, H. M. 1985. "Spatial and Temporal Variation in Settlement and Recruitment of Intertidal Barnacles.” Ecol. Monogr. 55: 313-332.

[2] Carrol. M. L., 1996. "Barnacle Population Dynamics and Recruitment Regulation in Southern Alaska.” Journal of Marine biology and ecology 199: 285-302.

[3] Jenkins, S. R. 2001. "Population Dynamics of the Intertidal Barnacle Semibalanus balanoides at Three European Locations: Spatial Scales of Variability.” Mar. Ecol. Prog. ser. 207-217.

[4] Zeinalipour, M., Hassanzadeh Kiabi, B., Shokri M. R., and Ardalan, A. A. 2014. "Population Dynamic and Distribution of Barbatia Decussata (Bivalvia: Arcidae) on
Rocky Intertidal Shores in the Northern Persian Gulf (Iran).” Tropical Zoology 27: 73-87.

[5] 5Zeinalipour, M. 2011. "The Study of Growth, Population Dynamic and Larval Recruitment of Bivalve, Mytilaster Lineatus, in Three Coastal Regions Amirabad, Khazarabad and Noor) in Southern Shores of Caspian Sea.” Iranian Journal of Biology 23: 584-595.

[6] 6Zeinalipour, M., Hassanzadeh Kiabi, B., Shokri, M. R. 2015. “Allometry, Condition Index and Secondary Production in Bivalve Barbatia Decussata on Rocky Intertidal Shores in the Northern Persian Gulf, Iran.” Journal of Environmental Biology 36: 1185-1192.

[7] 7Benny, N. C., Gray A. W. 2004. "Population Dynamics of the Acorn Barnacles, Tetraclita squamosa and Tetraclita japonica (Cirripedia: Balanomorpha), in Hong Kong.” Marine Biology 146: 149-160.

[8] 8Berntsson, K. M., and Jonsson, P. R. 2004. "Rejection of Unsuitable Substrata as a Potential of Aggregated Settlement in the Barnacle Balanus improvises.” Marine Ecology progress Series 75: 199-201.

[9] 9Birshtain, J. A., Vinogradov, L. T., Kondakov, N. N., Kun, M. S., and Astakhova, Romanova, T. V. 1968. "The Atlas of Caspian Sea Invertebrates.” Moscow, Pishevaja promyshlennost, p. 415.

[10] 10Grigorovich, I. A., Therriault, W. T. 2003. "History of Aquatic Invertebrate Invasions in the Caspian Sea." Biological Invasions 5: 103-115.

[11] 11Anderson, D. T. 1994. "Barnacle Structure, Function, Development.” Champan \& Hall publishing, p. 356.

[12] 12Spivey, H. R. 1989. "The Size Variable and Allometric Analysis in the Barnacle Genus Balanus.” Journal of natural history 23:1017-1032.

[13] 13Spivey, H. R. 1988. "Shell Morphometry in Barnacle: Quantification of Shape Change in Balanus.” Journal Zoology London 216: 265- 294.

[14] 14King, M. 1995. "Fisheries Biology, Assessment and Management.” Fishing News Books. p. 143.

[15] 15Silina, A. V., Ovsyannikova, I. I. 1999. "Growth of the Barnacle Balanus rostratus in the Sea of Japan.” Russian journal of Marine Biology 25: 18-22.

[16] Sanford, E., Bermudez, D. 1994. "Flow, Food Supply and Acorn Barnacle Population Dynamics.” Mar. Ecol. Prog. Ser. 104: 49-62.

[17] Buschbum, C. 2001. "Selective Settlement of the Barnacle, Semibalanus balanoides Facilitates its Growth and Reproduction on Mussel Bed in Wadden Sea." Helgol. Mar. Res 55: 128-134. 